\title{
Overexpression of the B-type Eph and ephrin genes correlates with progression and pain in human pancreatic cancer
}

\author{
ZHENHUI LU ${ }^{1 *}$, YONG ZHANG ${ }^{2 *}$, ZHAOYU LI $^{1}$, SONGNING YU ${ }^{1}$, GUOZHONG ZHAO $^{1}$, \\ MINGHAO LI ${ }^{1}$, ZUOZHEN WANG ${ }^{1}$, QI WANG ${ }^{1}$ and YINXUE YANG ${ }^{1}$ \\ ${ }^{1}$ Department of Hepatobiliary Surgery, General Hospital of Ningxia Medical University, Yinchuan City, \\ Ningxia Hui Autonomous Region 750004; ${ }^{2}$ Department of Surgical Oncology, The First Affiliated Hospital, \\ Medical School of Xi'an Jiaotong University, Xi'an 710061, P.R. China
}

Received September 5, 2011; Accepted December 15, 2011

DOI: $10.3892 / \mathrm{ol} .2012 .650$

\begin{abstract}
B-type erythropoietin-producing hepatocellular $($ EphB) receptors and their ephrin ligands are associated with aggressive behavior and poor prognosis in a number of malignancies. The aim of this study was to determine the association between the aberrant expression of these genes and prognosis in human pancreatic cancer. The expression of EphB and the ephrin ligands was determined using real-time quantitative reverse transcription PCR in 46 human primary pancreatic cancers. Overexpression of EphB2 and a more modest overexpression of ephrin-B2 mRNA were observed in more than $44 \%(20 / 46)$ of the pancreatic cancer specimens examined. Overexpression (>upper quartile) of EphB2 and ephrin-B2 was markedly associated with abdominal and/or back pain. Multivariate analysis identified the overexpression of EphB2 as an independent prognostic factor for disease-free and overall survival (both $\mathrm{P}<0.05$ ). The results of the present study suggest that an increased level of ephrin-B2, in the presence of a high expression of EphB2, leads to a more aggressive tumor phenotype and that EphB2 may be used as a prognostic factor in human pancreatic cancer.
\end{abstract}

\section{Introduction}

The B-type erythropoietin-producing hepatocellular (EphB) receptor tyrosine kinases and their ephrin ligands (ephrin-Bs) are involved in crucial aspects of the embryologic development and differentiation of the nervous system (1). However, the activities of EphB receptors and ephrin-Bs are not restricted to the neural system. Evidence suggests that certain members

Correspondence to: Dr Yinxue Yang or Dr Qi Wang, General Hospital of Ningxia Medical University, Yinchuan City, Ningxia Hui Autonomous Region 750004, P.R. China

E-mail: nyfyyyx@126.com

E-mail:wq-6562@163.com

*Contributed equally

Key words: B-type Eph, ephrin, human pancreatic cancer of the EphB family and their ligands are important in angiogenesis and oncogenesis (2-5). EphB2 and EphB3/ephrin-B signalling regulates cell sorting and cell migration through contact-mediated cell repulsion $(6,7)$. Overexpression of EphB2, EphB4 and ephrin-B1 has been described in gastric, colon and breast cancers (8-12). Although the ephrin-Eph system plays a number of roles in malignant tumors, to the best of our knowledge, little is known regarding its expression and role in pancreatic cancer. In the present study, we investigated the expression patterns of ephrin-B and EphB mRNA in a series of human pancreatic cancers and assessed the clinical significance of the gene expression to clinicopathological characteristics and patient prognosis.

\section{Patients and methods}

Patients. Cancer specimens from 46 patients with pancreatic cancer were obtained following partial duodenopancreatectomy (Whipple resection) at The First Affiliated Hospital of Xi'an Jiaotong University (Shaanxi, China), after obtaining informed consent from patients and approval by the ethics committee of the university. Specimens were divided into two sections. One was fixed in neutral-buffered formaldehyde and processed for histopathological evaluation and the other section was immediately frozen in liquid nitrogen and stored at $-80^{\circ} \mathrm{C}$ until use for the EphB and ephrin-B mRNA extraction and subsequent real-time quantitative reverse transcription PCR (qRT-PCR). Two normal pancreases, one pancreatic pseudocyst and one serous cystadenoma were used as non-malignant controls.

Between Feburary 2000 and September 2004, 46 patients at The First Affiliated Hospital were consecutively diagnosed with pancreatic cancer and underwent potentially curative resection of the pathologically confirmed adenocarcinoma of the pancreas with negative resection margins (R0). The patients received gemcitabine at $1,000 \mathrm{mg} / \mathrm{m}^{2}$ intravenously (IV) over 100 min every 2 weeks for 6 cycles. All 46 patients had a Karnofsky performance status of $\geq 60$ and adequate hematologic, renal and hepatic function as defined by a standard protocol in our department. Follow-up occurred at 3-month intervals for 1 year, then 6-month intervals for 3 years and yearly thereafter. The last date of patient follow-up was October 2007. Follow-up consisted of physical examination, 
Table I. Primers used in quantitative reverse transcription PCR.

\begin{tabular}{lll}
\hline Gene (Acc. No.) & \multicolumn{1}{c}{ Forward primer (5'-3') } & \multicolumn{1}{c}{ Reverse primer (5'-3') } \\
\hline EphB2 (NM_004442) & GAAGGAGCTCAGTGAGTACAACG & GCACCTGGAAGACATAGATGG \\
Ephrin-B2 (NM_004093) & GCAAGTTCTGCTGGATCAAC & AGGATGTTGTTCCCCGAATG \\
$\beta$-actin (NM_001101) & TCACCCACACTGTGCCCATCTACGA & CGGAACCGCTCATTCGCCAATGG \\
\hline
\end{tabular}

complete blood cell count, liver function testing, chest X-ray and CT scan as clinically indicated. Tumor stages were classified according to the American Joint Committee on Cancer (AJCC) classification (http://www.cancerstaging.org/). Pain was assessed in all patients prior to surgery using a standardized questionnaire as previously described (13).

Quantitative RT-PCR analysis of the EphB and ephrin-B expression. Total RNA was extracted from frozen samples with TRIzol reagent (Invitrogen, Carlsbad, CA, USA). DNaseItreated total RNA $(10 \mu \mathrm{g})$ was used for reverse transcription with Superscript II (Invitrogen). The resulting cDNA products were amplified using a LightCycler instrument. The total $10 \mu \mathrm{l}$ of reaction mixture consisted of a master mixture (LightCycler DNA master hybridization probes; Roche, Mannheim, Germany), $4.0 \mathrm{mM} \mathrm{MgCl}{ }_{2}, 0.25 \mu \mathrm{l}$ of EphB, ephrin-B or $\beta$-actin primers, $0.4 \mu \mathrm{M}$ of each probe and $1 \mu \mathrm{l}$ of template cDNA in a LightCycler capillary. The primers were designed using published sequences and are shown in Table I.

For EphB and ephrin-B amplification, $95^{\circ} \mathrm{C}(90 \mathrm{sec})$ for the hot start was followed by 42 rounds of amplification at $95^{\circ} \mathrm{C}$ (0 sec) for denaturation, $50^{\circ} \mathrm{C}(10 \mathrm{sec})$ for annealing and $72^{\circ} \mathrm{C}$ (10 sec) for extension, with a temperature slope of $20^{\circ} \mathrm{C} / \mathrm{sec}$, performed in the LightCycler. The same temperature profile was used for all experiments, except for an annealing temperature of $55^{\circ} \mathrm{C}$ for $\beta$-actin. External standards for EphB and ephrin-B mRNA and $\beta$-actin were known concentrations of MCF7 cell line (human breast cancer cell line) RNA prepared by 10 -fold serial dilutions. Each run consisted of five external standards, a negative control without a template and the patient samples. Relative mRNA in each sample was then automatically quantitated by reference to the standard curve constructed each time according to the LightCycler software.

Statistical analysis. Statistical analysis was performed using the SPSS-PC package (version 13.0; SPSS, Chicago, IL, USA). The $\chi^{2}$ and Fisher's exact tests were used to analyze the association between the expression of the EphB and ephrin-B genes, measured by qRT-PCR, and the clinicopathological features of pancreatic cancer. The thresholds (upper quartiles) were defined as positive or overexpression of the genes. Diseasefree and overall survival endpoints were analyzed. Survival time was calculated from the date of diagnosis until mortality (for overall survival) or, if the patient was still alive, until the last follow-up visit (disease-free and overall survival). Local, regional or distant tumor progression was taken into account as adverse events for disease-free survival. Mortality from any cause was considered for overall survival. The Kaplan-Meier method with the log-rank test was used to calculate survival rates and differences in survival curves. The Cox proportional hazards regression model with a stepwise procedure was used to analyze the simultaneous effect of prognostic factors. $\mathrm{P}<0.05$ was considered to indicate a statistically significant result.

\section{Results}

Gene expression. Initially, the expression of $7 \mathrm{EphB}$ and ephrin-B genes (EphB1-4,6 and ephrin-B1,2) were screened by real-time qRT-PCR on two normal pancreases, one pancreatic pseudocyst, one serous cystadenoma, as well as five pancreatic cancer specimens. The expression levels of EphB1, B3, B4, B6 and ephrin-B1 were relatively low in the normal and tumour samples and these genes were not considered further. Thus, EphB2 and ephrin-B2 were selected for further analysis.

Distribution of the EphB and ephrin-B genes in a series of 46 human pancreatic cancers. The distribution of pancreatic cancer specimens according to their EphB2 and ephrin-B2 mRNA expression is shown in Fig. 1. The median concentration of EphB2 was 0.21 (range, 0.007-4.26; lower quartile, 0.090; upper quartile, 0.40). The median concentration of ephrin-B2 was 0.093 (range, 0.002-2.41; lower quartile, 0.017; upper quartile, 0.15).

Correlation between EphB2 and ephrin-B2 expression status and clinicopathological characteristics. Table II shows the results of the $\chi^{2}$ and Fisher's exact tests of EphB2 and ephrin-B2 expression and various clinicopathological parameters.

No significant differences were found between the overexpressed and non-overexpressed EphB2 and ephrin-B2 groups with regard to age, gender or histological differentiation.

Overexpression of EphB2 and ephrin-B2 in pancreatic cancer specimens was more common in the the presence of lymph node metastasis ( 75.0 vs. $34.6 \%$ and 70.0 vs. $38.4 \%$, respectively; $\mathrm{P}<0.05$ ), in the classification of $\mathrm{T}$ factor ( $\mathrm{T} 1$ plus T2 vs. T3 plus T4: 75.0 vs. $23.1 \%$ and 65.0 vs. $30.7 \%$, respectively; $\mathrm{P}<0.05)$ and in the degree of pain $(90.0$ vs. $30.7 \%$ and 85.0 vs. $34.6 \%$, respectively; $\mathrm{P}<0.05$; Table II).

Uni- and multivariate analyses of prognostic factors in pancreatic cancer patients. One-year disease-free and overall survival rates were 39.0 and $30.0 \%$, respectively (Figs. 1 and 2). Forty-one patients had a tumor when they died and 38 patients experienced recurrence of a tumor: 21 in the liver, 10 in the lymph node, 3 in the peritoneum and 4 in other organs.

The prognostic significance of the expression of EphB2 and ephrin-B2 was analyzed for the disease-free and overall survival rates. Patients with a low EphB2 and ephrin-B2 expression had better 1-year survival rates than those with a high expression (disease-free, 55 vs. $15 \%$ and 43 vs. $35 \%$; overall, 52 vs. $0 \%$ and 44 vs. $11 \%$; all $\mathrm{P}<0.05$; Table III). 
Table II. Correlation between EphB2 and ephrin-B2 expression and clinicopathological characteristics of 46 patients with pancreatic cancer.

\begin{tabular}{|c|c|c|c|c|c|c|c|c|}
\hline \multirow[b]{2}{*}{ Characteristics } & \multicolumn{2}{|c|}{ EphB2 } & \multirow[b]{2}{*}{$\chi^{2}$} & \multirow[b]{2}{*}{ P-value } & \multicolumn{2}{|c|}{ Ephrin-B2 } & \multirow[b]{2}{*}{$\chi^{2}$} & \multirow[b]{2}{*}{ P-value } \\
\hline & $\begin{array}{c}\text { EphB2 - } \\
<\text { Upper quartile }\end{array}$ & $\begin{array}{r}\text { EphB2 + } \\
\geq \text { Upper quartile }\end{array}$ & & & $\begin{array}{l}\text { Ephrin-B2 - } \\
<\text { Upper quartile }\end{array}$ & $\begin{array}{c}\text { Ephrin-B2 + } \\
\geq \text { Upper quartile }\end{array}$ & & \\
\hline \multicolumn{9}{|l|}{ Age (years) } \\
\hline$<60$ & 12 & 10 & 0.067 & 0.796 & 13 & 9 & 0.113 & 0.736 \\
\hline$\geq 60$ & 14 & 10 & & & 13 & 11 & & \\
\hline \multicolumn{9}{|l|}{ Gender } \\
\hline Male & 12 & 9 & 0.006 & 0.938 & 13 & 8 & 0.456 & 0.500 \\
\hline Female & 14 & 11 & & & 13 & 12 & & \\
\hline \multicolumn{9}{|c|}{ Histological differentiation } \\
\hline Poorly & 11 & 6 & 1.645 & 0.439 & 11 & 6 & 1.645 & 0.439 \\
\hline Moderately & 12 & 9 & & & 12 & 9 & & \\
\hline Well & 3 & 5 & & & 3 & 5 & & \\
\hline \multicolumn{9}{|l|}{ Stage (AJCC) } \\
\hline I & 17 & 15 & 2.044 & 0.360 & 16 & 16 & 2.425 & 0.297 \\
\hline II & 4 & 4 & & & 5 & 3 & & \\
\hline III & 5 & 1 & & & 5 & 1 & & \\
\hline \multicolumn{9}{|l|}{ Pain } \\
\hline 0 & 8 & 1 & 18.592 & 0.000 & 7 & 2 & & \\
\hline 1 & 10 & 1 & & & 10 & 1 & & \\
\hline 2 & 5 & 5 & & & 5 & 5 & & \\
\hline 3 & 3 & 13 & & & 4 & 12 & 13.590 & 0.004 \\
\hline \multicolumn{9}{|l|}{$\mathrm{T}(\mathrm{pTNM})$} \\
\hline $\mathrm{T} 1$ & 16 & 5 & 16.626 & 0.001 & 15 & 6 & 9.084 & 0.028 \\
\hline $\mathrm{T} 2$ & 4 & 0 & & & 3 & 1 & & \\
\hline $\mathrm{T} 3$ & 1 & 10 & & & 2 & 9 & & \\
\hline $\mathrm{T} 4$ & 5 & 5 & & & 6 & 4 & & \\
\hline \multicolumn{9}{|c|}{ Lymph node metastasis } \\
\hline Absent & 17 & 5 & 7.389 & 0.007 & 16 & 6 & 4.506 & 0.034 \\
\hline Present & 9 & 15 & & & 10 & 14 & & \\
\hline
\end{tabular}

pTNM, pathological tumor-node-metastasis; AJCC, American Joint Committee on Cancer.

Univariate analysis revealed that the EphB2 and ephrin-B2 expression level, presence of lymph node metastasis, histological differentiation, the degree of pain and $\mathrm{T}$ stage of pathological tumor-node-metastasis (pTNM) staging system were significant prognosticators for disease-free and overall survival (Table III; Figs. 3 and 4).

Multivariate analysis with factors proven to be significant in the univariate analysis revealed that the EphB2 expression level and T stage of the pTNM staging system were independent prognostic factors for disease-free and overall survival. The presence of lymph node metastasis is an independent prognostic factor for overall survival only (Table IV).

\section{Discussion}

Eph receptors are the largest known family of receptor protein tyrosine kinases and are activated by interactions with cellsurface ligands termed ephrins, which are anchored on plasma membranes through either a glycosyl phosphatidylinositol linkage (ephrin-A) or a transmembrane domain (ephrin-B). The Ephs (receptors) and their ligands (ephrins) may be divided into two subclasses, $\mathrm{A}$ and $\mathrm{B}$, on the basis of sequence homology, structure and binding affinity (1-4). The Eph family of receptor kinases and their ligands are well known to be involved in fundamental developmental processes of the nervous system, including axon guidance, axon fasciculation, neural crest cell migration, acquisition of brain subregional identity and neuronal cell survival. Moreover, in recent years, ephrins and Ephs have been found to be expressed during the development of numerous human tumors, including melanoma, glioblastoma, lung carcinoma and breast carcinoma (2-5). However, information concerning the expression of ephrins and Ephs in pancreatic cancer is sparse. In particular, to the best of our knowledge, little is known regarding the expression and role of the different EphBs and ephrin-Bs in pancreatic cancer. In the current study, we investigated the expression 
Table III. Univariate analysis of clinicopathological characteristics for disease-free and overall survival of 46 patients with pancreatic cancer.

\begin{tabular}{|c|c|c|c|c|c|}
\hline Characteristics & No. of patients & $\begin{array}{c}\text { 1-year disease-free } \\
\text { survival rate \% }\end{array}$ & P-value & $\begin{array}{l}1 \text {-year overall } \\
\text { survival rate } \%\end{array}$ & P-value \\
\hline \multicolumn{6}{|l|}{ Age (years) } \\
\hline$<60$ & 22 & 20 & \multirow[t]{2}{*}{0.431} & 20 & \multirow[t]{2}{*}{0.534} \\
\hline$\geq 60$ & 24 & 53 & & 39 & \\
\hline \multicolumn{6}{|l|}{ Gender } \\
\hline Male & 21 & 27 & \multirow[t]{2}{*}{0.116} & 32 & \multirow[t]{2}{*}{0.357} \\
\hline Female & 25 & 49 & & 29 & \\
\hline \multicolumn{6}{|c|}{ Histological differentiation } \\
\hline Poorly & 17 & 50 & \multirow[t]{3}{*}{0.095} & 47 & \multirow[t]{3}{*}{0.124} \\
\hline Moderately & 21 & 42 & & 27 & \\
\hline Well & 8 & 0 & & 0 & \\
\hline \multicolumn{6}{|l|}{ Stage (AJCC) } \\
\hline I & 32 & 38 & \multirow[t]{3}{*}{0.251} & 29 & \multirow[t]{3}{*}{0.659} \\
\hline II & 8 & 19 & & 17 & \\
\hline III & 6 & 67 & & 50 & \\
\hline \multicolumn{6}{|l|}{ Pain } \\
\hline 0 & 9 & 74 & \multirow[t]{4}{*}{0.002} & 64 & \multirow[t]{4}{*}{0.004} \\
\hline 1 & 11 & 41 & & 41 & \\
\hline 2 & 10 & 37 & & 20 & \\
\hline 3 & 16 & 14 & & 7 & \\
\hline \multicolumn{6}{|l|}{ T (pTNM) } \\
\hline $\mathrm{T} 1$ & 21 & 60 & \multirow[t]{4}{*}{0.000} & 56 & \multirow[t]{4}{*}{0.000} \\
\hline $\mathrm{T} 2$ & 4 & 75 & & 50 & \\
\hline $\mathrm{T} 3$ & 11 & 0 & & 0 & \\
\hline $\mathrm{T} 4$ & 10 & 0 & & 0 & \\
\hline \multicolumn{6}{|c|}{ Lymph node metastasis } \\
\hline Absent & 22 & 58 & \multirow[t]{2}{*}{0.000} & 61 & \multirow[t]{2}{*}{0.000} \\
\hline Present & 24 & 0 & & 0 & \\
\hline \multicolumn{6}{|l|}{ EphB2 expression } \\
\hline$<$ Upper quartile & 26 & 55 & \multirow[t]{2}{*}{0.002} & 52 & \multirow[t]{2}{*}{0.000} \\
\hline$\geq$ Upper quartile & 20 & 15 & & 0 & \\
\hline \multicolumn{6}{|l|}{ ephrin-B2 } \\
\hline$<$ Upper quartile & 26 & 43 & \multirow[t]{2}{*}{0.520} & 44 & \multirow[t]{2}{*}{0.042} \\
\hline$\geq$ Upper quartile & 20 & 35 & & 11 & \\
\hline
\end{tabular}

pTNM, pathological tumor-node-metastasis; AJCC, American Joint Committee on Cancer.

patterns of ephrin-B and EphB mRNA in a series of human pancreatic cancers and demonstrated that the overexpression of EphB2 is correlated with progression and pain in human pancreatic cancer. Our observations indicate that EphB1, B3, B4, B6 and ephrin-B1 are coordinately silenced in the majority of pancreatic cancers and non-tumorous samples. The mechanism of the silencing of EphB expression in pancreatic cancer and non-tumorous samples remains uncharacterized, but in the great majority of cancers, downregulation of EphB receptors occurs at the mRNA level $(4,7)$.

Our results clearly demonstrate that the overexpression of EphB2 and ephrin-B2 had a significantly higher incidence with lymph node metastasis, advanced classification of $\mathrm{T}$ factor and a higher degree of pain. Patients with low EphB2 and ephrin-B2 expression yielded better 1-year survival rates than those with a high expression. The proportion of individuals surviving pancreatic cancer is extremely low and the length of time between diagnosis and mortality is typically short, usually less than six months (13). Approximately 2 out of 10 individuals with pancreatic cancer live for at least one year after their cancer is found. Fewer than $4 \%$ are likely to be alive after 5 years (http://www.cancerstaging.org/) (13). Thus, 1-year rates were used as the standard way of looking at a patient's outlook in this study. Multivariate analysis identified 
Table IV. Multivariate analysis of clinicopathological characteristics for disease-free and overall survival of patients with pancreatic cancer.

\begin{tabular}{|c|c|c|c|c|}
\hline Characteristics & Odds ratio & $95 \% \mathrm{CI}$ & $\chi^{2}$ value & P-value \\
\hline \multicolumn{5}{|l|}{ Disease-free survival } \\
\hline EphB2 expression & 4.480 & $1.206-16.640$ & 5.017 & 0.025 \\
\hline Lymph node metastasis & 1.568 & $0.405-6.073$ & 0.424 & 0.515 \\
\hline Histologic differentiation & 1.041 & $0.537-2.019$ & 0.014 & 0.905 \\
\hline $\mathrm{T}(\mathrm{pTNM})$ & 1.757 & $1.012-3.048$ & 4.014 & 0.045 \\
\hline Pain & 1.579 & $0.995-2.504$ & 3.767 & 0.052 \\
\hline \multicolumn{5}{|l|}{ Overall survival } \\
\hline EphB2 expression & 5.109 & $1.633-15.983$ & 7.855 & 0.005 \\
\hline Lymph node metastasis & 5.901 & $1.881-18.513$ & 9.257 & 0.002 \\
\hline Histologic differentiation & 1.017 & $0.557-1.856$ & 0.003 & 0.957 \\
\hline $\mathrm{T}(\mathrm{pTNM})$ & 2.046 & $1.273-3.286$ & 8.757 & 0.003 \\
\hline Pain & 1.070 & $0.702-1.631$ & 0.098 & 0.754 \\
\hline
\end{tabular}

CI, confidence interval; pTNM, pathological tumor-node-metastasis.

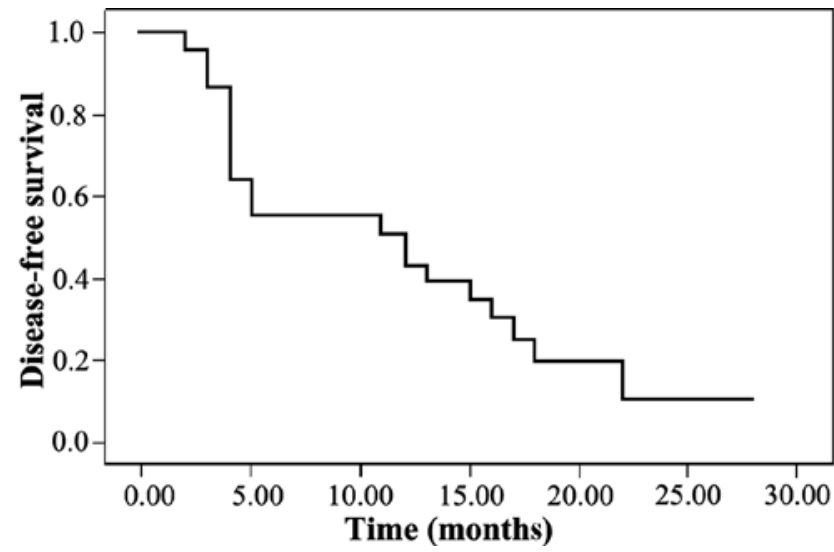

Figure 1. The 1-year disease-free survival rate of the 46 pancreatic cancer patients was $39.0 \%$.

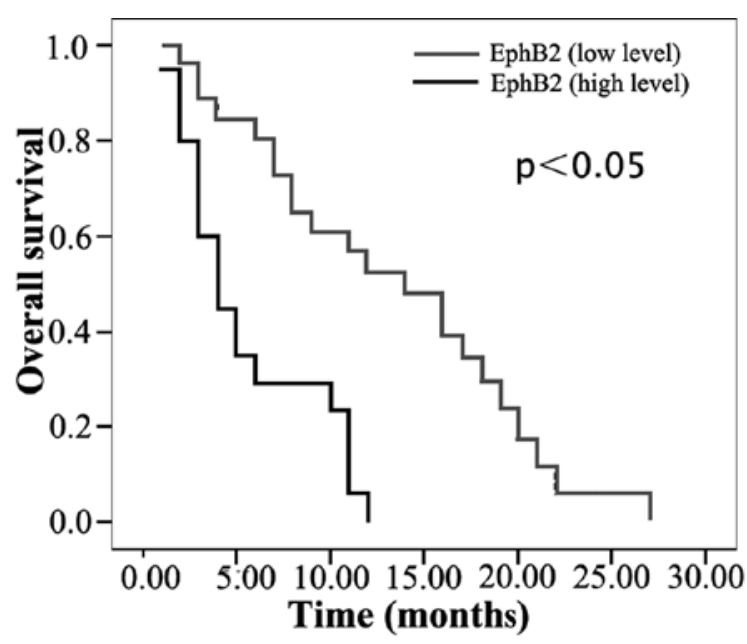

Figure 3. The expression level of EphB2 was a significant prognostic factor for the overall survival of patients with pancreatic cancer.

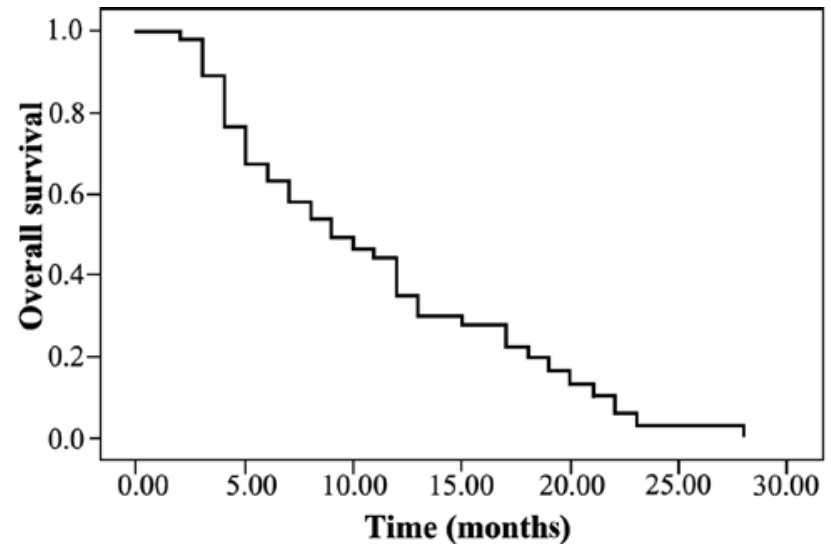

Figure 2. The 1-year overall survival rate of the 46 pancreatic cancer patients was $30.0 \%$.

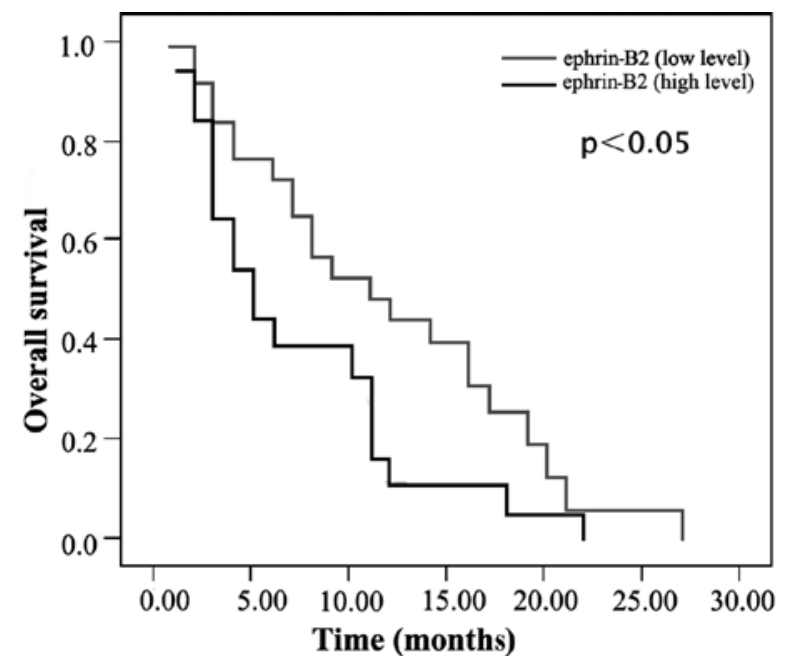

Figure 4. The expression level of ephrin-B2 was a significant prognostic factor for the overall survival rate of patients with pancreatic cancer. 
the level of EphB2 expression as an independent prognostic factor for disease-free and overall survival $(\mathrm{P}<0.01, \mathrm{P}<0.0001$, respectively). Our results are consistent with those of previous studies, which indicated that an increased expression of EphB2 in breast cancer was associated with poor overall survival and that there was a clear trend that high levels of the EphB2 protein were negatively associated with disease-free survival. However, this is contrary to previous data presented in colorectal cancer that suggest that EphB2 expression is a good prognostic factor. The discrepancy may be explained by fundamental differences in the role of EphB2 in cancers of the solid and hollow organs. The Eph receptor families and their ligands are well known to signal complicated cell processes, which may result in distinct or occasionally even opposing effects on cell behaviour depending on context (14).

Pain affects cancer prognosis and has been shown to be an independent prognostic factor in pancreatic cancers (13). Overexpression of EphB2 is correlated with a higher degree of pain, the mechanism for which is not yet apparent. However, the ephrin-B-EphB receptor signalling has been shown to contribute to neuropathic pain by regulating excitability of nociceptive-related neurons in dorsal root ganglion and dorsa horn and the synaptic plasticity at the spinal level (15). Moreover, ephrin-B2 siRNA may be a potential therapeutic agent for neuropathic pain (16).

In conlusion, high levels of EphB2 expression are associated with shortened survival in patients with pancreatic cancer and multivariate analyses suggest that EphB2 is an independent prognostic factor. The Eph family of receptor tyrosine kinases is an attractive candidate for therapeutic targets. Previous studies have developed a monoclonal antibody, peptide or small molecules against EphB2 in an attempt to block its activation (17-19), which may be applied as a potential remedy in pancreatic cancer as there are few treatment options available for patients with a disease with such a high mortality rate, resulting in poor outcomes.

\section{References}

1. Coulthard MG, Duffy S, Down M, Evans B, Power M, Smith F, Stylianou C, Kleikamp S, Oates A, Lackmann M, Burns GF and Boyd AW: The role of the Eph-ephrin signalling system in the regulation of developmental patterning. Int J Dev Biol 46: 375-384, 2002.

2. Klein R: Bidirectional signals establish boundaries. Curr Biol 9: R691-R694, 1991.

3. Gale NW, Holland SJ, Valenzuela DM, Flenniken A, Pan L, Ryan TE, Henkemeyer M, Strebhardt K, Hirai H, Wilkinson DJ, Pawson T, Davis S and Yancoupoulos GD: Eph receptors and ligands comprise two major specificity subclasses and are reciprocally compartmentalised during embryogenesis. Neuron 17: 9-19, 1996.
4. Boyd AW and Lackmann M: Signals from Eph and ephrin proteins: a developmental tool kit. Sci STKE 112: re20, 2001.

5. Hirai H, Maru Y, Hagiwara K, Nishida J and Takaku F: A novel putative tyrosine kinase receptor encoded by the eph gene. Science 238: 1717-1720, 1987.

6. Batlle E, Henderson JT, Beghtel H, van den Bron MM, Sancho E, Huls G, Meeldijk J, Robertson J, van de Wetering M, Pawson T and Clevers H: Beta-Catenin and TCF mediate cell positioning in the intestinal epithelium by controlling the expression of EphB/ ephrin B. Cell 111: 251-263, 2002.

7. Batlle E, Bacani J, Begthel H, Jonkheer S, Gregorieff A, van de Born M, Malats N, Sancho E, Boon E, Pawson T, Gallinger S, Pals S and Clevers H: EphB receptor activity suppresses colorectal cancer progression. Nature 435: 1126-1130, 2005.

8. Kataoka H, Tanaka M, Kanamori M, Yoshii S, Ihara M, Wang YJ, Song JP, Li ZY, Arai H, Otsuki Y, Kobayashi T, Konno H, Hanai $\mathrm{H}$ and Sugimura $\mathrm{H}$ : Expression profile of EFNB1, EFNB2, two ligands of EPHB2 in human gastric cancer. J Cancer Res Clin Oncol 28: 343-348, 2002.

9. Stephenson SA, Slomka S, Douglas EL, Hewett PJ and Hardingham JE: Receptor protein tyrosine kinase EphB4 is up-regulated in colon cancer. Int J Dev Biol 46: 375-384, 2002.

10. Berclaz G, Flutsch B, Altermatt HJ, Rohrback H, Djonov V, Ziemiecki A, Dreher E and Andres AC: Loss of EphB4 receptor tyrosine kinase protein expression during carcinogenesis of the human breast. Pain 139: 168-180, 2008.

11. Nikolova Z, Djonov V,Zuercher G, Andres AC and Ziemiecki A: Cell-type specific and estrogen dependent expression of the receptor tyrosine kinase EphB4 and its ligand ephrin B2 during mammary gland morphogenesis. J Cell Sci 111: 2741-2751, 1998.

12. Liu W, Ahmad SA, Jung YD, Reinmuth N, Fan F, Bucana CD and Ellis LM: Co-expression of ephrin-Bs and their receptors in colon carcinoma. Cancer 94: 934-939, 2002.

13. Zhang Y, Dang C, Ma Q and Shimahara Y: Expression of nerve growth factor receptors and their prognostic value in human pancreatic cancer. Oncol Rep 14: 161-171, 2005.

14. Holmberg $\mathrm{J}$ and Frisen $\mathrm{J}$ : Ephrins are not only unattractive. Trends Neurosci 25: 239-243, 2002.

15. Kobayashi H, Kitamura T, Sekiguchi M, Homma MK, Kabuyama Y, Konno S, Kikuchi S and Homma Y: Involvement of EphB1 receptor/EphrinB2 ligand in neuropathic pain. Spine (Phila Pa 1976) 32: 1592-1598, 2007.

16. Song XJ, Zheng JH, Cao JL, Liu WT, Song XS and Huang ZJ: EphrinB-EphB receptor signaling contributes to neuropathic pain by regulating neural excitability and spinal synaptic plasticity in rats. Pain 139: 168-180, 2008.

17. Mao W, Luis E, Ross S, Silva J, Tan C, Crowley C, Chui C, Franz G, Senter P, Koeppen H and Polakis P: EphB2 as a therapeutic antibody drug target for the treatment of colorectal cancer. Cancer Res 64: 781-788, 2004.

18. Toledo-Sherman L, Deretey E, Slon-Usakiewicz JJ, Ng W, Dai JR, Foster JE, Redden PR, Uger MD, Liao LC, Pasternak A and Reid N: Frontal affinity chromatography with MS detection of EphB2 tyrosine kinase receptor. 2. Identification of smallmolecule inhibitors via coupling with virtual screening. J Med Chem 48: 3221-3230, 2005.

19. Koolpe M, Burgess R, Dail M and Pasquale EB: EphB receptorbinding peptides identified by phage display enable design of an antagonist with ephrin-like affinity. J Biol Chem 280: 17301-17311, 2005. 